\title{
Use of some antiplatelet agents appears safe in patients undergoing transurethral resection of bladder tumor
}

\author{
Kyle A. Richards \\ Department of Urology, The University of Wisconsin-Madison, Madison, WI, USA \\ Correspondence to: Kyle A. Richards, MD, FACS. Department of Urology, The University of Wisconsin-Madison, Madison, WI, USA. \\ Email: richardsk@urology.wisc.edu. \\ Provenance: This is a Guest Editorial commissioned by Section Editor Xiao Li (Department of Urology, Jiangsu Cancer Hospital \& Jiangsu Institute \\ of Cancer Research \& Nanjing Medical University Affiliated Cancer Hospital, Nanjing, China). \\ Comment on: Prader R, De Broca B, Chevallier D, et al. Outcome of Transurethral Resection of Bladder Tumor: Does Antiplatelet Therapy Really \\ Matter? Analysis of a Retrospective Series. J Endourol 2017;31:1284-8.
}

Submitted Mar 22, 2018. Accepted for publication Apr 09, 2018.

doi: 10.21037/tau.2018.04.09

View this article at: http://dx.doi.org/10.21037/tau.2018.04.09

Romain Prader and colleagues evaluated the impact of antiplatelet (AP) drugs on length of stay (LOS) in patients undergoing transurethral resection of bladder tumor (TURBT). LOS was used as the primary endpoint as an easy to measure surrogate to account for post-op issues assuming a longer LOS means more post-op issues largely secondary to bleeding. The article is timely and important given the increasingly high incidence of AP use in patients undergoing TURBT. This clinical scenario is commonplace and we are often asked by patients, anesthesiologists, primary care physicians, cardiologists, etc. Should we stop the aspirin and/or clopidogrel prior to Mr. Smith's TURBT? Is it safe? Is it wise? Will stopping the AP drug lead to an increased risk of a major adverse cardiac event? Will continuing the AP drug result in more bleeding in the perioperative setting?

In my mind, I have always believed it safe to perform TURBT in patients taking aspirin (ASA) $81 \mathrm{mg}$. Romain Prader and colleagues study essentially confirms my intuition and my own clinical experience. I recommend all my patients on ASA $81 \mathrm{mg}$ whether for primary or secondary prevention continue their ASA $81 \mathrm{mg}$ without any adulteration during and after TURBT. Less is known about the safety of higher doses of ASA and anecdotally bleeding risk seems higher at higher doses. Therefore, I usually recommend patient taking higher doses to decrease to an $81 \mathrm{mg}$ dose 1 week prior to TURBT. Additional studies on higher doses of ASA would be nice to assess the safety in these settings.

Clopidogrel poses a higher risk of bleeding in the perioperative setting as confirmed in this study. My interpretation of the data by Romain Prader and colleagues is that most or all the patients in their cohort interrupted their clopidogrel 5 days prior to TURBT. Yet even in this scenario, the risk of bleeding and prolongation of the hospital stay was significant. Clopidogrel clearly raises the stakes in comparison to ASA $81 \mathrm{mg}$ alone. My personal clinical experience has been similar and I attempt to negotiate (usually with the cardiologist) a longer period of clopidogrel abstinence prior to TURBT (7 days). Once again, the literature is lacking (to the best of my knowledge) in regard to the outcomes of patients undergoing TURBT while actively taking clopidogrel.

In conclusion, as urologists we must strike a balance between risk of bleeding and risk of major adverse cardiac event. Patients with recent coronary stents that may require TURBT are extremely challenging to manage especially if they require dual AP therapy without interruption. Do you wait to do the TURBT when the patient can interrupt their clopidogrel or do you proceed to TURBT without delay? Additional studies are needed on risk of bleeding 
after TURBT in patients taking novel anticoagulation medications such as apixaban or dabigatran.

\section{Acknowledgements}

None.

Cite this article as: Richards KA. Use of some antiplatelet agents appears safe in patients undergoing transurethral resection of bladder tumor. Transl Androl Urol 2018;7(Suppl 2):S236-S237. doi: 10.21037/tau.2018.04.09

\section{Footnote}

Conflicts of Interest: The author has no conflicts of interest to declare. 